\title{
Migraine-related disability and co-morbid depression among migraineurs in Ethiopia: a cross-sectional study
}

\author{
Biniyam Alemayehu Ayele (D) and Yared Mamushet Yifru
}

\begin{abstract}
Background: Migraine headache is a neurologic disorder which mainly affects younger and productive segment of population. Migraine not only causes pain; but also affects quality of life in terms of low productivity and economic loss. The main aim of this study was to examine migraine-related disability, co-morbid depression, and relationship between the two.

Methods: A cross-sectional study was conducted among migraineurs who visited two neurology referral clinics. The study was conducted between June 1 st 2016 to December 30 ${ }^{\text {th }}$ 2016. Migraine disability assessment score [MIDAS] and patient health questionnaire [PHQ-9] were used to assess disability and depression, respectively.

Results: A total of 70 patients participated in the study. Fifty-three (74.3\%) of our study participants were women. Fifty one (72.9\%) study participants were between age group 20-40 years. Migraine without aura was the most common subtype (70\%); migraine with aura accounted for the other $28.6 \%$. The mean ( \pm SD) headache frequency and intensity was $23.4 \pm 14.9$ days and $7.4 \pm 1.2$ respectively. Major depressive disorder was common in this group (41.4\%). The mean MIDAS and PHQ-9 scores were $46.7 \pm 30$ and $9.2 \pm 4.4$ respectively. More than two-thirds (74.3\%) of our participants had severe disability. We found a statistically significant correlation between migraine-related disability and co morbid depression among our participants $(r=0.318, p$-value $=0.007)$.

Conclusion: The positive correlation observed between migraine-related disability and co-morbid depression warrant routine screening and treatment of disability and depression in migraineurs; In addition, the observed high degree of disability among our participants may indicate sub optimal treatment of these patients.
\end{abstract}

Keywords: Migraine, Depression, Disability, Co morbidity, PHQ-9, MIDAS

\section{Background}

Migraine is a disabling neurologic disorder; characterized by recurrent and often unilateral headaches. Migraine causes substantial psychological and economic impact on the individual and society at large [1]. It is three times more common in women than men. Symptoms such as: nausea, vomiting, photophobia and phonophobia are often present in most migraineurs; and a few report osmophobia [2]. Migraine is common. According to the Global Burden of Disease survey (GBD 2010), its estimated prevalence was close to $15 \%$ among the general population [3]. In patients with migraine, recurrent episodes have the potential

\footnotetext{
* Correspondence: biniyam.alemayehu@aau.edu.et; biniyam.a7@gmail.com Department of Neurology, College of Health Science, Addis Ababa Univeristy, PO BOX: 6396, Addis Ababa, Ethiopia
}

to progress to the more frequent and severe attacks of chronic migraine $(\mathrm{CM})$, which affects $2.4 \%$ of the general, population [4]. Migraine headache is classified into two broad categories; migraine with aura and migraine without aura. Migraine without aura is a clinical syndrome characterized by headache and associated autonomic features but without any warning symptoms, also known as aura. Migraine with aura is characterized by focal neurological symptoms that may precede or sometimes accompany headache [5].

Ethiopia is the second most populous country in Africa, with a population of more than 100 million. Population-based studies done in Ethiopia in the past two decades have shown the prevalence of migraine headache to be between 3 to $17.7 \%$ [6, 7]. In a recent 
Ethiopian study of migraine in relation to psychiatric co-morbidities, participants with moderate to severe depressive symptoms had a 3-fold increased odds of migraine compared with those with minimal or no depressive symptoms, and the odds of migraine increased with increasing severity of depressive symptoms [8]. Migraine is documented as a major cause of disability worldwide. According to the World Health Report, migraine is the 19th leading cause of Years of Life with Disability. In addition, the global Burden of Headache reported migraine as the leading cause of disability among neurological disorders; and globally migraine was ranked as the seventh highest cause of disability [9-11].

It has long been known that migraine is associated with a number of medical and psychiatric conditions. One of the most common psychiatric co-morbidity is depression; which is reported in up to $80 \%$ of patients, especially in chronic migraine [12]. Patients with migraine are two to four times more likely to develop lifetime major depression as compared to those without migraine [13]. Different Studies suggest that the presence of depression in migraine patients significantly increase the level of disability that these patients experience in their daily life. As such, depression is associated with a greater incidence of severe disability. Patients with severe disability are six times more prone to have depression compared to those with lower disability $[13,14]$.

The Presence of clinical depression in a migraineurs is not only associated with more frequent and severe headaches, it also has the risk of transforming episodic migraine to chronic migraine. Chronic migraine is more disabling and often refractory to treatment [15]. The co-existence of depression can also adversely affect the quality of life by increasing the burden of the disease $[15,16]$. We did this study with the main objective, to determine the relationship between migraine-related disability co-morbid depression among migraineurs having a follow-up at two neurology referral clinics in Addis Ababa, Ethiopia.

Even though multiple studies done elsewhere confirm the positive correlation between migraine-related disability and co-morbid depression, to the authors' best knowledge, this is the first study of its kind to assess disability and depressive symptoms and their association among migraineurs in Ethiopia. As a result, we believe this study will be a baseline study for Ethiopia and other sub-Saharan countries.

\section{Methods}

This is an observational, cross-sectional, hospital based study conducted between June 1st 2016 to December 30th 2016. Demographic variables included in this study were age, sex, marital status, educational status, occupation and religion. The study was conducted at Tikur Anbessa
Specialized Hospital (TASH), a university teaching hospital and the only tertiary level referral hospital in Ethiopia; located at the heart of Addis Ababa and Zewditu Memorial Hospital (ZMH), a government referral hospital also located in Addis Ababa having affiliation to Addis Ababa University.

Data collection was started after obtaining formal approval letter from Institutional Review Board (IRB) of College of Health Sciences, Addis Ababa University. Inclusion criteria was all migraine patients attending both neurology referral clinics during the study period in which a diagnosis of migraine (both migraine with aura and migraine without aura) was made by a neurologist based on the International Classification of Headache Disorders (ICHD-3) and having age greater than 13 years (by tradition patients with age $>13$ years are seen at adult outpatients clinic in our hospital) [5]. An exclusion criterion was migraine patients having additional diagnosis of other primary headache disorders like tension type headache (Tables 1 and 2).

A total of 72 patients with confirmed diagnosis of migraine were interviewed. Two patients were excluded because of the co-occurrence of tension type headache with migraine headache. The demographic and clinical data were collected from structured survey questionnaire. Disability was assessed by Migraine Disability Assessment Score [MIDAS], well validated disability screening tool. MIDAS is simple to administer, easily interpreted and has been validated in population-based samples [17]. MIDAS is graded in to four grades; Grade I (little or no disability, scores range $0-5$ ), grade II (mild disability, scores range 6-10), grade III (moderate disability, scores range 11-20), and grade IV (severe disability, 21 or greater).

The Patient Health Questionnaire [PHQ-9] was used to screen depression. PHQ-9 is a nine-question screening instrument for depressive symptoms based on Diagnostic and Statistical Manual of Mental Disorders (DSM) IV criteria to diagnose depression and also a validated tool in African population $[18,19]$. PHQ-9 has also been validated in

Table 1 Diagnostic criteria for migraine without aura

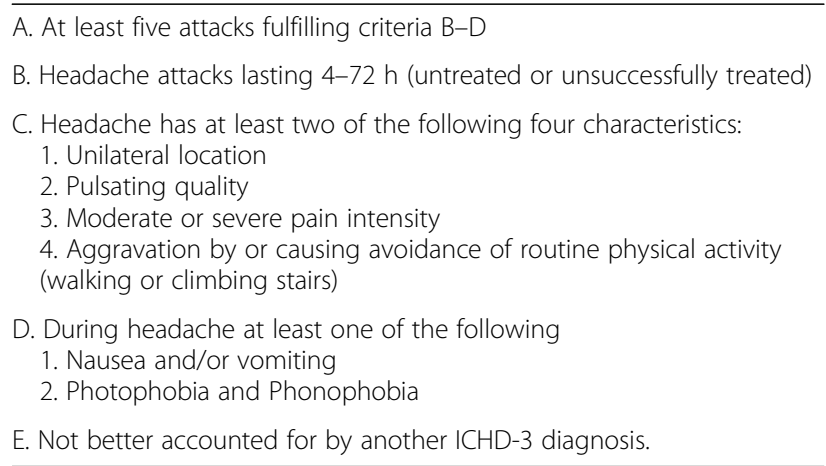

Note. ICDH. The International Classification of Headache Disorders: 3rd edition. Cephalalgia. 2013; 33:9; 629-808 
Table 2 Diagnostic criteria for migraine aura:-

A. At least two attacks fulfilling criteria B-C
B. One or more of the following fully reversible aura symptoms:
1. visual
2. sensory
3. speech and/or language
4. motor
5. brainstem
6. retinal
C. At least two of the following four characteristics:
1. At least one aura symptom spreads gradually over 5 min, and/or
two or more symptoms occur in succession
2. Each individual aura symptom lasts $5-60$ min 1
3. At least one aura symptom is unilateral2
4. The aura is accompanied, or followed within 60 min, by headache
D. Not better accounted for by another ICHD-3 diagnosis, and transient
ischemic attack has been excluded.

Note. ICDH. The International Classification of Headache Disorders: 3rd edition. Cephalalgia. 2013; 33:9; 629-808

Ethiopia [20]. All the interviews were conducted by the two investigators; both neurologists. The statistical analysis was performed using SPSS version 20.0 computer program. Chi square test with $p$ values and crude odds ratio (OR) with a $95 \%$ confidence interval $(\mathrm{CI})$ were used to determine to statistical associations of selected variables.

A $p$-value $<0.05$ was considered significant. Descriptive summaries were employed for socio-demographic and other clinical variables. Analytical statistics including bivariate analysis with Spearman's correlation were performed to determine the correlation between; disability and depression.

\section{Results}

Of the seventy migraine patients interviewed at the two Neurology clinics in Addis Ababa, three-fourths (74.3\%) were female. More than two third (72.9\%) of our study participants were between age group 20-40 years, 5.7\% were $<20$ years and $18.6 \%$ of them were $>40$ years (Table 3). Thirty-three (47.1\%) were married and 8 (11.4\%) of them were divorced. Thirty four $(48.6 \%)$ patients were government employees, 9 (12.9\%) were students and only $2(2.9 \%)$ were unemployed. One-third (28.6\%) of the study participants had a secondary school education and $27.1 \%$ had a Bachelor's degree or above educational level (Table 3).

Among women migraineurs, $31.5 \%$ experienced worsening or occurrence of their migraine headache during menses. The majority of our study participants $(70 \%)$ had migraine without aura, while $28.6 \%$ of our participants reported auras of different type prior to their
Table 3 Frequency distribution of socio-demographic characteristics of migraine patients. $N=70$

\begin{tabular}{|c|c|c|}
\hline Variables & Number & Percent \\
\hline \multicolumn{3}{|l|}{ Gender } \\
\hline Male & 18 & 25.7 \\
\hline Female & 52 & 74.3 \\
\hline \multicolumn{3}{|l|}{ Age groups } \\
\hline $14-20$ & 4 & 5.7 \\
\hline $20-30$ & 28 & 40 \\
\hline $30-40$ & 25 & 35.7 \\
\hline $40-65$ & 13 & 18.6 \\
\hline \multicolumn{3}{|l|}{ Marital status } \\
\hline Single & 23 & 32.9 \\
\hline Married & 33 & 47.1 \\
\hline In a relationship & 5 & 7.1 \\
\hline Divorced & 8 & 11.4 \\
\hline Widowed & 1 & 1.5 \\
\hline \multicolumn{3}{|l|}{ Occupational status } \\
\hline Government employee & 34 & 48.6 \\
\hline Student & 9 & 12.9 \\
\hline Private business & 13 & 18.6 \\
\hline House wife & 7 & 10.0 \\
\hline Farmer & 2 & 2.9 \\
\hline Jobless & 2 & 2.9 \\
\hline Other & 3 & 4.3 \\
\hline \multicolumn{3}{|l|}{ Educational status } \\
\hline Illiterate & 2 & 2.9 \\
\hline Read and write only & 3 & 4.3 \\
\hline Primary education (1-8) & 8 & 11.4 \\
\hline Secondary education (8-12) & 20 & 28.6 \\
\hline Diploma & 18 & 25.7 \\
\hline Degree and above & 19 & 27.1 \\
\hline
\end{tabular}

migraine attack. Whether patients with aura did have at times headache episodes without accompanying aura was not specifically queried. One patient found to have diagnosis of ophthalmoplegic migraine (1.4\%).

The majority of participants had a diagnosis of migraine by a physician less than five years ago (54.3\%), while $24.3 \%$ had it for $5-10$ years. The rest of our participants $(21.4 \%)$ had migraine for more than 10 years (Table 4). Among our study participants $31.5 \%$ of them are on medications for migraine prophylaxis; including 25.1\% on Amitriptyline, 5.9\% on propranolol and 0.5\% on Imipramine (Table 4).

The mean PHQ-9 score in our study was $9.2 \pm 4.4$. Severe depressive symptoms were present in $14.3 \%$ of study participants, while $45.7 \%$ had a PHQ-9 score between 5 and 9, indicative of mild depressive disorder. Many (41.4\%) of our 
Table 4 Frequency distribution of headache-related characteristics of migraine patients. $N=70$

\begin{tabular}{lll}
\hline Migraine headache worsening/ & & $\%$ \\
occurring during Menses & Yes & 31.5 \\
& No & 68.5 \\
Subtype of Migraine & Total & 100 \\
& Migraine without aura & 70.0 \\
& Migraine with aura & 28.6 \\
& Ophtalmopelgic migraine & 1.4 \\
Duration of Migraine headache & Total & 100 \\
& $<05$ years & 54.3 \\
& 5-10 years & 24.3 \\
& $>10$ years & 21.4 \\
& Total & 100 \\
Migraine prophylaxis & Amitriptyline & 25.1 \\
& Propranolol & 5.9 \\
& Imipramine & 0.5 \\
& Total & 31.5 \\
\hline
\end{tabular}

participants fulfilled criteria for major depressive disorder (Table 5). The mean MIDAS score was $46.7 \pm 30$. Over two-third of our patients (74.3\%) had severe disability, defined as MIDAS score $\geq 21$, while $15.7 \%$, had moderate and $8.6 \%$ mild disability. Only $1.4 \%$ of our study participants had little or no disability (Table 6).

Spearman's correlation was used to examine associations between co-morbid depression and disability. There was a significant $(p=0.007)$ correlation between severe disability (Grade IV) and depression (PHQ-9, Grade II-IV) for both minor and major depressive disorders, compared to non-depressed patients (PHQ-9, Grade I). Spearman's coefficient of this correlation is $r=0.318$, indicating positive correlation between depression and severe disability (Table 7). Depression was associated with occurrence of severe disability; severe disability was found to be 8 times more common in patients with depression in comparison to those having no depression. Depressed migraine patients were five times more likely to have severe disability $(p=0.007)$ compared to non-depressed patients. In our study; we also found a statistically significant $(p=0.002)$

Table 5 Patient Health Questioners (PHQ-9) score of migraine patients. $N=70$

\begin{tabular}{lll}
\hline PHQ-9 & Mean(SD) & $9.2 \pm 4.4$ \\
\hline Minimal (0-4) & $\%$ & 12.9 \\
Mild (5-9) & $\%$ & 45.7 \\
Moderate(10-14) & $\%$ & 27.1 \\
Severe(>=15) & $\%$ & 14.3 \\
\hline
\end{tabular}

Table 6 Migraine Disability Assessment Scale (MIDAS) score of migraine patients. $N=70$

\begin{tabular}{lll}
\hline MIDAS Scoring & Mean(SD) & $46.7 \pm 30$ \\
\hline Little or no disability (0-5) & $\%$ & 1.4 \\
Mild disability (6-10) & $\%$ & 8.6 \\
Moderate disability (11-20) & $\%$ & 15.7 \\
Severe disability (> =21) & $\%$ & 74.3 \\
\hline
\end{tabular}

association between migraine-related disability and migraine occuring during menses (Table 8).

\section{Discussion}

Most of our participants were females, and two-thirds of them had migraine without aura. Significant proportion of the study participants fulfilled the criteria for major depressive disorders, and many of them had severe disability scores. We also found a strong correlation between disability and co- morbid depression among migraineurs. Most of the migraine- related clinical characteristics, like female preponderance, high proportion of migraine without aura observed in our study, are comparable to prior published studies on migraine from both developing and developed countries [21].

We observed one patient with diagnosis of ophthalmoplegic migraine in our study; which we also saw in other reported cases from Ethiopia in the past few years [22, 23]. When we compare our findings with the study done by Pavlović 2015 and his colleagues, in which 60\% of women with migraine reported an association between migraine attack and menses [24], our finding show much lower than this, only one third of our participants reported an association between migraine attack and menses; which could be attributable to lack of awareness among our patients about the possible association between menses and migraine and not using the headache diary, which often is helpful in tracking such precipitating causes.

Close to half of our participants are government employees (Table 3) and their diagnosis of migraine was made in less than five years (Table 4). This might be due to the fact that the study was done in the capital city, Addis Ababa, where better neurologic service was started only recently.

Table 7 Correlation between degree of disability and depression among migraine patients. $N=70$

\begin{tabular}{|c|c|c|c|c|}
\hline & \multicolumn{2}{|l|}{ MIDAS score } & \multirow[t]{2}{*}{$P$-value } & \multirow{2}{*}{$\begin{array}{l}\text { Spearman } \\
\text { coefficient }\end{array}$} \\
\hline & $\begin{array}{l}\text { MIDAS Grade } \\
<\text { IV }\end{array}$ & $\begin{array}{l}\text { MIDAS Grade } \\
\text { IV }\end{array}$ & & \\
\hline PHQ-9 Grade II-IV & 47 & 14 & 0.007 & 0.318 \\
\hline PHQ-9 Grade I & 5 & 4 & & \\
\hline Total & 52 & 18 & & 70 \\
\hline
\end{tabular}

Spearman coefficient $=0.318$; indicative of positive correlation. Statistically significant $P$-value $<0.001,95 \% \mathrm{Cl}$ 
Table 8 Association between disability and migraine during menses among migraine patients. $N=70$

\begin{tabular}{|c|c|c|c|c|}
\hline & \multicolumn{2}{|l|}{ MIDAS score } & \multirow[t]{2}{*}{ Total } & \multirow{2}{*}{$\begin{array}{l}P \text {-value } \\
0.02\end{array}$} \\
\hline & MIDAS Grade < IV & $\overline{\text { MIDAS Grade IV }}$ & & \\
\hline \multicolumn{5}{|c|}{ Headache During menses } \\
\hline Yes & 7 & 12 & 19 & \\
\hline No & 34 & 17 & 51 & \\
\hline Total & 41 & 29 & 70 & \\
\hline
\end{tabular}

Statistically Significant $P$-value $<0.05,95 \% \mathrm{Cl}$

Two factors may explain the higher prevalence of migraine-related disability among our study participants. First, the fact that this is a hospital based study and most likely many of our patients had prolonged treatment by general practitioners in other facilities then referred for better assessment and treatment by a neurologist. Secondly, the suboptimal treatment and lack of screening for management of disability and co -morbid events like depression may also contribute to the higher level of morbidity.

An interesting finding in this study is high proportion of our study participants were on amitriptyline for migraine prophylaxis, yet significant proportion had persistent major depressive disorder (MDD). This may be due to use of low doses of amitriptyline, which is inadequate to treat depression as well as lack of psychotherapy.

Regarding co-morbid depression based on PHQ-9 score; the mean PHQ-9 (Table 5) of our study is comparable to the finding from Canadian study, in which the mean PHQ-9 score was 8 [25]. Among our study participants, significant proportion of them fulfilled the criteria for Major depressive disorder with PHQ-9 $\geq 10$ (Table 5), which is comparable to one meta-analysis which reported the incidence of depression in migraineurs to be between 8.6 to $47.9 \%$ [26].

Our mean MIDAS score (Table 6) with higher than those reported from studies done in Turkey $(19.3 \pm 12.3)$ and Italy $(12 \pm 8.2)[27,28]$. More than two third of our study participants had severe disability with a MIDAS score $\geq 21$ (Table 6), which is much higher than the result from a similar study from Turkey, in which severe disability was noted in $40 \%$. One study done in South Korea reported a much higher MIDAS score of $54.1 \pm$ 49.9 , mainly among chronic migraine patients in their study [29].

In our study, depression was associated with greater incidence of severe disability. Our finding is comparable to those results reported from South Korea [29] and another study reported by JL Brandes et al. [30] which showed patients with MDD had significant association with severe disability [MIDAS Grade IV], compared to non-depressed migraineurs. We also found a statistically significant ( $\mathrm{p} 0.02$ ) association between migraine-related disabilities in migraine occurring during menses; this finding highlights the need to routinely look for aggravation of migraine during menses, so that we may be able to optimize both abortive and preventive migraine treatment in such situation.

Limitations of our study include a small sample size and the fact that this is hospital-based study with likelihood of over representation of more severe cases. As a result we acknowledge the limited generalizability of these findings to the whole population. In addition, for both the screening tools we were dependent on patient's ability to remember symptoms in the past two weeks for depression screening and three months for disability, which could have introduced recall bias.

\section{Conclusion}

We conclude from our analysis that there is a higher proportion of severe disability and co-morbid depression with positive correlation between the two in migraine. Our findings show the importance of screening for disability and depression in migraine patients, as this might guide our management approach and impact their overall therapeutic outcome.

Finally, this study points to the need for large scale longitudinal, observational study in Ethiopia to evaluate the relationship between migraine-related disability and co-morbid depression.

\section{Abbreviations}

MIDAS: Migraine Disability Assessment Score; PHQ-9: Patient Health Questioner 9; TASH: Tikur Anbessa Specialized Hospital; ZMH: Zewditu Memorial Hospital; MDD: Major Depressive Disorder

\section{Acknowledgements}

- I would like to extend my heartfelt gratitude all the nursing staffs at both neurology referral clinics were the survey was conducted, above all my heartfelt gratitude goes to all participants of this study.

- We would like to extend our greatest appreciation to prof. Douglas Dulli who spends his valuable time in correcting the typo and language errors of our manuscript.

\section{Funding}

- No funding was received from any organization or individuals.

\section{Availability of data and materials}

- All datasets on which the conclusions of the manuscript rely; to be available as spread sheets documents and available from the corresponding author on reasonable request from the editors. 


\section{Authors' contributions}

BAA and YMY participated in data acquisition, data analysis, data interpretation and manuscript editing and preparation. Both authors read and approved the final manuscript.

\section{Authors' information}

1. Biniyam Alemayehu Ayele, MD, Assistant professor of neurology

- Staff at department of neurology, College of Health Science, Addis Ababa Univeristy

- Teach clinical neurology to both undergraduate medical students and graduate students including neurology residents.

- Work as consultant neurologist at Tikur Anbessa Specialized University Hospital and Zewditu Memorial Hospital.

- Involved in different research projects in field of neuroscience in Ethiopia.

- Have special interest in Headache disorders, Clinical neurophysiology and movement disorders.

- Member of International Headache society(IHS)

- Email: biniyam.alemayehu.aau.edu.et/biniyam.a7@gmail.com

2. Yared Mamushet Yifru, MD, MSc, Headache specialist

- Assistant professor of Neurology at department of neurology, College of Health Science Addis Ababa Univeristy, Ethiopia.

- Teach clinical neurology to both undergraduate medical students and graduate students including neurology residents.

- Work as consultant neurologist at Tikur Anbessa Specialized University Hospital and Zewditu Memorial Hospital.

- Involved in different research projects in field of neuroscience in Ethiopia.

- Have special interest in Headache disorders, strokes and movement disorders.

_ Email: yared_mty@yahoo.com

\section{Ethics approval and consent to participate}

- Ethical approval letter was obtained from Institutional Review Board of the College of Health Sciences, Addis Ababa University, with protocol number: 017/16/Neuro on meeting No: 005/16, on May25, 2016.

- All participants/their guardians gave informed written consent before taking part in the study.

- The research was performed in accordance with the Declaration of Helsinki.

- Written informed consent was obtained from patients and for those under the age of 18 years from their legal guardians before proceeding to interview.

\section{Consent for publication}

- All authors agreed on the decision to publish this manuscript.

- Participants consent for publication: Not applicable.

\section{Competing interests}

- The authors declare that they have no competing interests.

\section{Publisher's Note}

Springer Nature remains neutral with regard to jurisdictional claims in published maps and institutional affiliations.

Received: 8 February 2018 Accepted: 25 June 2018

Published online: 02 July 2018

\section{References}

1. L. M. Bloudek, M. Stokes, D., C. Buse,T. K. Wilcox, R. B. Lipton, P. J. Goadsby,S. F. Varon, A. M. Blumenfeld, Z. KatsaravaJ. Pascual, M. Lanteri-Minet, P. Cortelli, P. Martelletti et al. cost of healthcare for patients with migraine in five European countries- results from the international burden of migraine study (IBMS). J Headache Pain.2012; 13:361-378.

2. Robert BD, Joseph J, John CM, Scott LP. Headache and other craniofacial pain. In: Ivan G, Todd JS, Carrie ER, Jonathan HS, editors. Bradely, Neurology in clinical practice. 7th ed. China: Elsevier; 2016. p. 1695-706.
3. Vos T, Flaxman AD, Naghavi M, Lozano R, Michaud C, Ezzati M, Shibuya K, Salomon JA, Abdalla S, Aboyans V, Abraham J, Ackerman I, Aggarwal R, Ahn SY, Ali MK, Alvarado M, Anderson HR, Anderson LM, Andrews KG, Atkinson C, Baddour LM, Bahalim AN, Barker-Collo S, Barrero LH, Bartels DH, Basáñez MG Baxter A, Bell ML, Benjamin EJ, Bennett D, et al. Years lived with disability (YLDs) for 1160 sequelae of 289 diseases and injuries 1990-2010: a systematic analysis for the global burden of disease study 2010. Lancet. 2012;380:2163-96.

4. Castillo J, Munoz P, Guitera V, et al. Epidemiology of chronic daily headache in the general population. Headache. 1998;39:190-6.

5. ICDH. The International Classification of Headache Disorders: 3rd edition. Cephalalgia. 2013;33(9):629-808.

6. Tekle Haimanot R, Seraw B, Forsgren L, Ekbom K, Ekstedt J. Migraine, chronic tension-type headache, and cluster headache in an Ethiopian rural community. Cephalalgia. 1995; https://doi.org/10.1046/j.1468-2982.1995.1506482.x.

7. Mihila Z, Tekle-Haimanot R, Dawit DK, Thomas H, Steiner TJ. The prevalence of primary headache disorders in Ethiopia. J Headache Pain. 2016; https://doi.org/10.1186/s10194-016-0704-z.

8. Bizu G, Lee BP, Seblewongel L, Markos T. Migraine and psychiatric comorbidities among sub-Saharan African adults. Headache. 2013; https://doi.org/10.1111/j.1526-4610.2012.02259.x.

9. Leonardi M, Steiner TJ, Scher AT, Lipton RB, et al. The global burden of migraine-measuring disability in headache disorders with WHO's classification of functioning, disability and health (ICF). J Headache Pain. 2005:6:429-40.

10. World Health Organization. Atlas of Headache Disorders and Resources in the World. Geneva: World Health Organization; 2011. www.who.int. ISBN 9789241564212.

11. Steiner TJ, Stovner LJ, Birbeck GL, et al. Migraine - the seventh disabler. J Headache Pain. 2013;14:1.

12. Mercante JP, Peres MF, Vera G, Eliova Z, Marcio AB, et al. DEPRESSION IN CHRONIC MIGRAINE. ArqNeuropsiquiatr. 2005;63(2):217-20.

13. Breslau N, Lipton RB, et al. Co morbidity of migraine and depression. Neurology. 2003;60:1308-12.

14. Breslau N, Davis GC, et al. Migraine and major depression - a longitudinal study. HEADACHE J HEAD AND FACE PAIN. 1994;34:387-93.

15. Jette N., et al. Comorbidity of migraine and psychiatric disorders - a national population-based study. Headache 2008;48; 4: 501-16.

16. Shehbaz N, Ali S, et al. MIGRAINE - COMORBIDITY WITH DEPRESSION. Pak J Med Sci. 2007;23(1):95-9.

17. Stewart WF, et al. Reliability of the migraine disability assessment score in a population based sample of headache sufferers. Cephalalgia. 1999;19(2):107-14.

18. Monahan PO, Shacham E, Reece M, et al. Validity/reliability of PHQ-9 and PHQ-2 depression scales among adults living with HIV/AIDS in western Kenya. J Gen Intern Med. 2009;24:189-97.

19. Omoro SA, Fann JR, Weymuller EA, Macharia IM, Yueh B, et al. Swahili translation and validation of the patient health Questionnaire-9 depression scale in the Kenyan head and neck cancer patient population. Int J Psychiatry Med. 2006;36:367-81.

20. Charlotte H, Girmay M, Medhin S, et al. Validity of brief screening questionnaires to detect depression in primary care in Ethiopia. J Affect Disord. 2015;186:32-9.

21. Gobel H, Petersen-Braun M, Soyka D, et al. The epidemiology of headache in Germany - a nationwide survey of a representative sample on the basis of the headache classification of the international headache society. Cephalalgia. 1994;14:97-106.

22. Ayele BA, Mengistu G, Wako AA, et al. Adult variant of ophthalmologic migraine with recurrent 6th cranial nerve palsy in 25yrs old Ethiopian patient case report. J Neurol Stroke. 2016; https://doi.org/10.15406/jnsk.2016.04.00158.

23. Arasho BD, et al. Ophthalmoplegic migraine in a 15-year-old Ethiopian case report and literature review. J Headache Pain. 2009;10(1):45-9.

24. Jelena MP, Walter FS, Christa AB, Jennifer AG, Haiyan S, Dawn CB, Richard $B L$, et al. Burden of migraine related to menses - results from the AMPP study. J Headache Pain. 2015; https://doi.org/10.1186/s10194-015-0503-y.

25. Amoozegar $F$, et al. The prevalence of depression and the accuracy of depression screening tools in migraine patients. Report. Univeristy of Calgary. Alberta APRIL. 2014

26. Antonaci F, et al. Migraine and psychiatric comorbidity -a review of clinical findings. J Headache Pain. 2011;12(2):115-25.

27. Eraslan D, Dikmen PY, et al. The relation of sexual function to migrainerelated disability, depression and anxiety in patients with migraine. J Headache Pain. 2014;15:32. 
28. CORALLO F COLAMC, et al. Assessment of anxiety, depressive disorders and pain intensity in migraine and tension headache patients. ActaMedicaMediterranea. 2015;31:615.

29. Kim SY, Park SP, et al. The role of headache chronicity among predictors contributing to quality of life in patients with migraine - a hospital-based study. J Headache Pain. 2014;15:68.

30. J I B, Roberson SC, et al. The relationship between co-morbid depression and migraine disability. Advanced studies in medicine. 2002;2:16.

Ready to submit your research? Choose BMC and benefit from:

- fast, convenient online submission

- thorough peer review by experienced researchers in your field

- rapid publication on acceptance

- support for research data, including large and complex data types

- gold Open Access which fosters wider collaboration and increased citations

- maximum visibility for your research: over $100 \mathrm{M}$ website views per year 